\title{
Intelligent Painting Process Planner for Robotic Bridge Painting
}

\author{
Yong Bai, Ph.D., P.E., M.ASCE ${ }^{1}$
}

\begin{abstract}
Due to increased government regulations on environment, health, and safety, the cost of on-site bridge painting has quadrupled over the past several years. The construction industry faces a great challenge in how to control the increased costs of bridge painting and meet the regulations at the same time. A possible solution to address this challenge is to develop a robotic bridge painting system. The development of the robotic system can be justified by the potential improvements in safety and productivity. This paper presents the development and testing of an Intelligent Painting Process Planner. The Planner, built based on bridge feature scheme, is the key component for the robotic bridge painting system that integrates the painting process planning, robot path planning, cost optimization, and quality control functions. During the development process, lab experiments were conducted to determine the values of painting process planning parameters and coating thickness distribution functions. Field tests demonstrated that the prototype robotic bridge painting system achieved the specified painting quality using the parameter values provided by the Planner. Areas that need to be improved in the future were also identified.
\end{abstract}

DOI: $10.1061 /(A S C E) 0733-9364(2007) 133: 4(335)$

CE Database subject headings: Painting; Bridges; Robotics.

\section{Introduction}

There are two reasons for using paint. The first, and oldest reason, is to beautify and enhance the appearance of an object. The second reason is to protect an object from its environment or wear inflicted through use. Using the current technologies, a typical on-site bridge painting operation involves sandblasting the bridge surface to remove old paint (most of the time lead based) and rust, and then painting it to protect the surface from the environment. Painting an on-site bridge is not only labor intensive, but also dangerous. When a contractor accepts the job he/she must establish educational and medical programs to prepare workers for the job. All workers must attend a safety workshop where they learn about the hazards of lead-based paint, clean up techniques, and other procedures to ensure they adhere to all Occupational Safety and Health Administration (OSHA) regulations. Workers are also subject to medical examinations before, during, and after the project. Doctors test them for chemicals in their blood and to ensure they breathe well enough to use the breathing equipment. In addition to educational and medical programs, the contractor must encapsulate the area to be painted. The reason for this is to keep lead-based paint fragments and dust from entering the environment. The encapsulation structure, usually consisting of a steel framework covering with panels made of aluminum or fiberglass,

\footnotetext{
${ }^{1}$ Assistant Professor, Dept. of Civil, Environmental, and Architectural Engineering, Univ. of Kansas, 2150 Learned Hall, 1530 W. 15th St., Lawrence, KS 66045-7609. E-mail: ybai@ku.edu

Note. Discussion open until September 1, 2007. Separate discussions must be submitted for individual papers. To extend the closing date by one month, a written request must be filed with the ASCE Managing Editor. The manuscript for this paper was submitted for review and possible publication on October 19, 2005; approved on December 5, 2006. This paper is part of the Journal of Construction Engineering and Management, Vol. 133, No. 4, April 1, 2007. (CASCE, ISSN 0733-9364/2007/ 4-335-342/\$25.00.
}

must meet OSHA's standards. The standards require a ventilation system to move and clean the air within the work area. Other stipulations require the contractor to provide a decontamination area, so workers can shower and put on clean clothes before leaving the project work area. Over the past several years, the cost of on-site bridge painting has quadrupled due to increasing environmental and health regulations (ODOT 2004). The current situation calls for innovative research that addresses the need for new technologies in the area of on-site bridge painting that will ease costs and meet government regulations at the same time.

\section{Applications of Robotic Painting Systems}

Automated and robotic systems for construction applications have advanced dramatically over the past few years (Navon and Shpatnitsky 2005; Cho et al. 2004; Kim et al. 2003; Akinci et al. 2002). These systems were developed to reduce labor requirements and costs, increase productivity, and improve quality and safety. In the specific area of robotic surface painting, research has being carried out by several universities and industries throughout the world. Surface painting is one of the construction operations that is very suitable for robotics because it is labor intensive, consists of simple and repetitive motions (Skibniewski and Hendrickson 1988). Kumagai Gumi, Ltd. (Tokyo, Japan) has developed the "FR-1" surface-finishing robot for walls (Tokioka et al. 1989). Researchers at the University of Texas at Austin have successfully developed a prototype automated machine system to blast and paint large diameter steel storage tanks common in the petrochemical industry (Warne 1994). The prototype design, the Automated Surface Finishing System, was completed in 1990.

The researchers at the North Carolina State University developed a robotic bridge paint removal system (Moon and Bernold 1995). The purpose of the system is to provide a safe working environment during a bridge paint removal operation. The first 
prototype was successfully demonstrated in August 1994. Based on this success, Bai and Bernold studied the process planning parameters that control the robotic bridge painting quality (Bai and Bernold 2001). Process planning is the fundamental step needed to sequence a task and to describe how a particular task will be accomplished (Chang et al. 1991). For robotic bridge painting operations, process planning is the function that establishes what parameters are needed to paint a piece of steel bridge surface and to achieve the specified quality.

\section{Problem Statement and Research Objectives}

Due to increased on-site bridge painting cost and government regulations, the construction industry faces a great challenge in how to control the increase of the bridge painting cost and meet government regulations at the same time. A possible solution to address this challenge is to develop a robotic bridge painting system that can perform the painting operations in place of human beings. To make robotic bridge painting a reality, there is a need to develop a planning and control model to manage the bridge painting process so that the required painting quality can be achieved. The objectives of this research were to develop and test an Intelligent Painting Process Planner $\left(\mathrm{IP}^{3}\right)$, which is the key element in the planning and control model for the on-site robotic bridge painting. The $\mathrm{IP}^{3}$, built based on bridge feature scheme, integrates the painting process planning, robot path planning, cost optimization, and quality control functions. It is configured in two major components, which are (1) the process planning generator; and (2) the parameter editor. A total of eight process planning parameters are provided by the generator, which can be modified by the parameter editor if necessary. These are: (1) the air pressure; (2) the fluid pressure; (3) the spray gun pitch angle; (4) the spray gun roll angle; (5) the distance between spray gun and bridge surface; (6) the spray gun moving speed; (7) the number of spray runs; and (8) the reposition distance between two adjacent spray runs. Parameters 1-6 are used to set up the spray gun, and 7 and 8 are used for robot path planning.

Values for some parameters (e.g., air and fluid pressures) were determined through lab experiments based on the criterion of achieving the required quality. Other parameters (e.g., distance and speed) were determined based on achieving both the quality and the minimum total direct cost for bridge painting. The requirements for bridge painting quality include two elements: (1) the coating thickness; and (2) the coating appearance. Paint on steel bridge is applied in a series of coats ranging from 1 to 6 mils [one mil is equal to $0.025 \mathrm{~mm}(0.001 \mathrm{in}$.) ]. Each project specifies its own level of quality, which is the minimum thickness that must be satisfied. An appearance check is a necessary step in ensuring that the surface will not corrode more rapidly than expected. Common appearance failures include: (1) edge failure; (2) dry spray; (3) holidays/pinholes; and (4) runs/sags (Pinney 1985). Besides the lab experiments, field tests were conducted to validate the developed $\mathrm{IP}^{3}$.

Topics closely related to the development of the $\mathrm{IP}^{3}$ are presented in the rest of the paper. These include (1) bridge features; (2) planning and control model; (3) lab experiments; (4) $\mathrm{IP}^{3}$ development; (5) field experiments; and (6) contributions, conclusions, and recommendations.

\section{Bridge Features}

The concept of "feature" is used in many fields. However, a unified definition of feature does not exist (Fu et al. 1993). There are

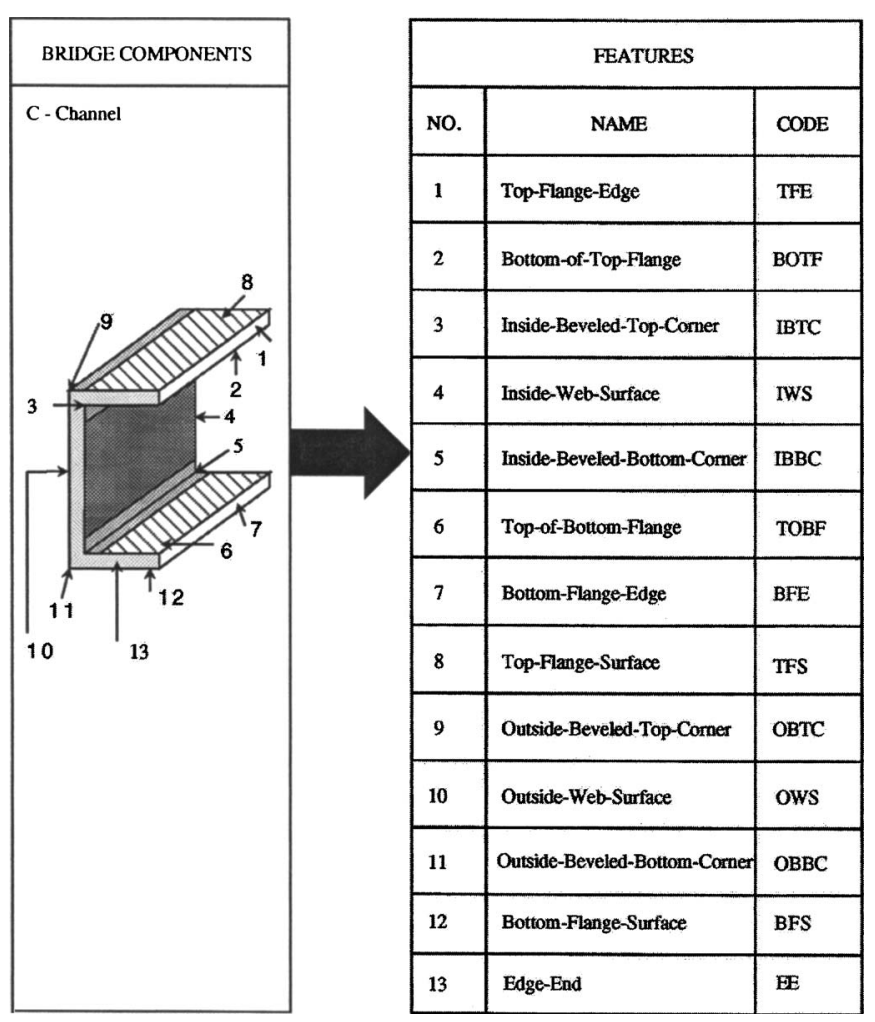

Fig. 1. Feature characterization for bridge C-channel beam

form features (also called shape features or geometric features), design features, and manufacturing features. In other words, the definition of a feature is application dependent. In this research, features are defined as meaningful representations of geometry that can be used to construct the spray painting process. Thus, painting operations on a bridge can be broken down into painting on each bridge feature. Each feature corresponds to a set of process planning parameters that are needed for setting up the spray gun. These parameters are: (1) the air pressure; (2) the fluid pressure; (3) the spray gun pitch angle; (4) the spray gun roll angle; (5) the distance between spray gun and bridge surface; and (6) the spray gun moving speed.

To create a "catalog" of features for the steel bridge, bridge design drawings provided by the North Carolina Department of Transportation (NCDOT) were studied. The highway steel bridge structure was organized into four basic components: (1) beam (or girder); (2) bracing; (3) bearing; and (4) connections. In cooperation with the engineers at NCDOT Bridge Maintenance Department, basic features for each of the four components were developed. An example of features for a C-channel beam is shown in Fig. 1.

An object can be identified easily using human eye. Based on this fact, a vision system was developed for the operator to detect bridge features. The vision system includes: (1) a color video camera; (2) Image-Pro Plus software (IP Plus); and (3) vision software that allows the video camera to be directly integrated with a personal computer and IP Plus. The camera was mounted on the end of the manipulator that allows the operator to view the bridge structures under the deck. In addition to displaying the image, the vision system can be used to calculate the dimensions of the areas that need to be painted. 


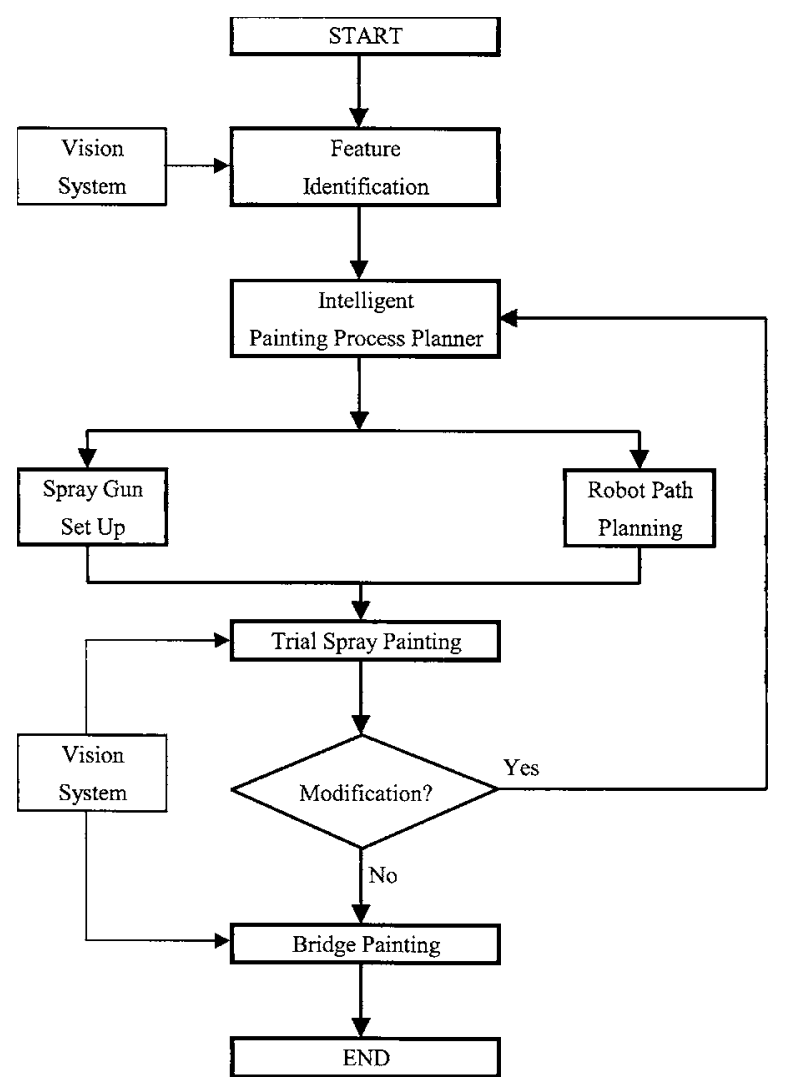

Fig. 2. Planning and control model for robotic bridge painting

\section{Planning and Control Model for Robotic Bridge Painting}

After the bridge features were defined, the next task was to develop a planning and control model for robotic bridge painting, shown in Fig. 2. At the beginning of the model, an operator identifies the bridge feature(s) using the vision system. Given the feature(s) and along with the specified quality, on-site physical constraints, painting area dimensions, and thickness distribution functions, the $\mathrm{IP}^{3}$ will generate a set of painting process planning parameters for setting up the spray gun and planning the robot path. Then, the operator will perform a trial spray painting and monitor the process using the vision system in real time. If there is no quality problem, the painting operation will continue. Otherwise, modification is needed. The operator provides the information about the problem to the $\mathrm{IP}^{3}$. The $\mathrm{IP}^{3}$ addresses the problems and a new set of parameters will be given to the operator. Then, the operator resets the robotic system and starts painting again. This process will continue until the painting is satisfactory. Sometimes it is impossible to set up the robotic painting system right the first time, so modifications are necessary.

The key component in the planning and control model is the $\mathrm{IP}^{3}$. To develop the $\mathrm{IP}^{3}$, the following questions arose: (1) what are parameter values to achieve the required quality for different bridge features; and (2) what are the coating thickness distribution functions for different spray operations. Laboratory experiments were conducted to answer these questions.

\section{Laboratory Experiments}

Factorial experiments were conducted to investigate the values of the process planning parameters for the bridge features and the

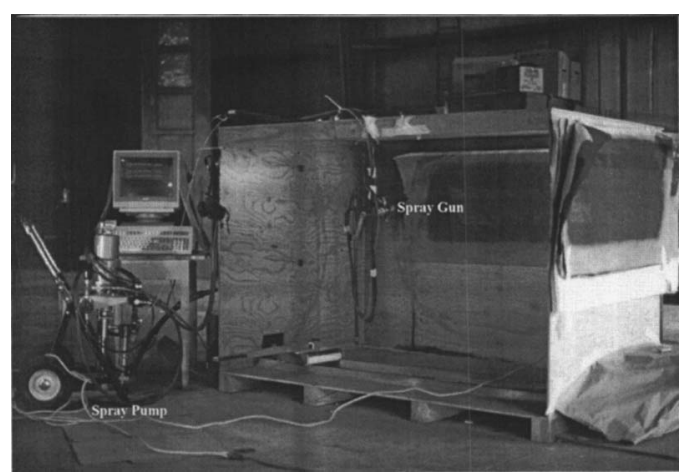

Fig. 3. Layout of experimental facilities

thickness distribution functions. A factorial experiment is one in which responses are observed for every combination of factor levels (Freund and Wilson 1993). In this research the initial responses were the coating thickness and appearance. During the experiments, the analysis on the appearance was dropped because the coating appearance was acceptable for all the experiments. The factors were air pressure; fluid pressure; pitch angle; roll angle; distance; and moving speed. The various settings of these factors in the experiments are called levels. The experimental apparatus included: (1) a Graco AA3000 automatic air-assisted airless spray gun; (2) a Graco pump; (3) a stepper motor; (4) a Centroid motion controller; and (5) a personal computer. Fig. 3 shows the layout of the experiment facilities.

In the laboratory experiments, steel strips were used as substitutes for the bridge features. The data collection procedure, which was kept the same during the entire experiment process, and experiment results on the web-surface features (including insideweb-surface and outside-web-surface features) were published (Bai and Bernold 2001). This paper presents the experiment's results on the inside-beveled-bottom-corner (IBBC) feature that have not been previously published.

\section{Experiment Setting on the IBBC Feature}

The IBBC feature is formed by two flat surfaces with a $90^{\circ}$ angle. Fig. 4 presents the experiment setting for the IBBC feature. The spray gun roll angle was set at zero degrees during the entire experiment. Initially, the spray pitch angle was set at $45^{\circ}$ for the development of the thickness regression model for the IBBC feature. Later, it was changed to $30^{\circ}$ and then $15^{\circ}$ to examine how the thickness distribution functions changed accordingly. The air and fluid pressures were set at 137.8 and $3,445 \mathrm{kPa}$ (20 and
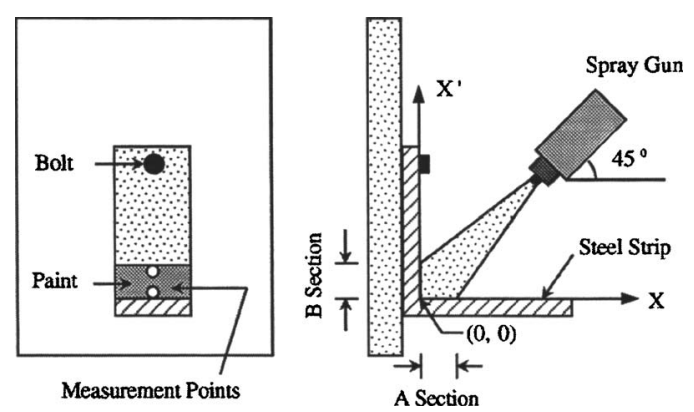

Fig. 4. Experiment setting for the IBBC feature 


\begin{tabular}{|c|c|c|c|c|c|c|c|c|c|c|c|c|c|}
\hline \multirow{4}{*}{$\begin{array}{l}\text { Distance } \\
(\mathrm{cm})\end{array}$} & \multirow{4}{*}{$\begin{array}{l}\text { Speed } \\
(\mathrm{cm} / \mathrm{s})\end{array}$} & \multicolumn{12}{|c|}{ Spray gun angle (degrees) } \\
\hline & & \multicolumn{4}{|c|}{15} & \multicolumn{4}{|c|}{30} & \multicolumn{4}{|c|}{45} \\
\hline & & \multicolumn{2}{|c|}{ Section A } & \multicolumn{2}{|c|}{ Section B } & \multicolumn{2}{|c|}{ Section A } & \multicolumn{2}{|c|}{ Section B } & \multicolumn{2}{|c|}{ Section A } & \multicolumn{2}{|c|}{ Section B } \\
\hline & & $\theta$ & $\mathrm{C}$ & $\theta$ & $\mathrm{C}$ & $\theta$ & $\mathrm{C}$ & $\theta$ & $\mathrm{C}$ & $\theta$ & $\mathrm{C}$ & $\theta$ & $\mathrm{C}$ \\
\hline 20.3 & 35.6 & 0.34 & 2.37 & - & - & 0.42 & 2.37 & - & - & 0.24 & 1.92 & 0.24 & 1.92 \\
\hline 25.4 & 30.5 & 0.26 & 2.40 & - & - & 0.36 & 2.46 & 0.12 & 1.51 & 0.22 & 1.79 & 0.22 & 1.79 \\
\hline 30.5 & 25.4 & 0.28 & 2.89 & 0.22 & 1.61 & 0.24 & 2.72 & 0.20 & 2.04 & 0.14 & 2.18 & 0.14 & 2.18 \\
\hline
\end{tabular}

Note:- = data was not recorded because the coating on the surface was not thick enough.

$500 \mathrm{psi}$ ), respectively. The air and the fluid pressures are selected based on the coating thickness specified in the project specification. Most of the bridge painting projects require 1.5 mils coating thickness for each layer. Results of the initial laboratory experiments indicated that the air and the fluid pressures needed to be set at 137.8 and $3,445 \mathrm{kPa}$ (20 and $500 \mathrm{psi}$ ), respectively, for 1.5 mils thickness (Bai and Bernold 2001). The speed had two factor levels that were 25.4 and $35.6 \mathrm{~cm} / \mathrm{s}$ (10 and $14 \mathrm{in.} / \mathrm{s}$ ). There were three factor levels, $20.3,25.4$, and $30.5 \mathrm{~cm}(8,10$, and 12 in.), for the distance.

\section{Data Analyses}

A total of six experiments were conducted in the lab to develop the thickness regression model for the IBBC feature. Twelve thickness measurement points were taken for each experiment. SAS Software was used to analyze the thickness measurement data. Results of the data analyses indicated that the thickness regression model for the IBBC feature was

$$
Y_{t}=3.23-0.075 X_{1}-0.075 X_{2}
$$

where $Y_{1}=$ coating thickness; $X_{1}=$ speed; and $X_{2}=$ distance between the spray gun and the corner of IBBC feature (point 0,0 in Fig. 4). The multiple coefficient of determination $\left(R^{2}\right)$ was 0.98 for the model. Depending on the presence of obstacles around the bridge structure, the spray gun may be set up at $20.3 \mathrm{~cm}$ ( 8 in.) from the structure with the speed at $35.6 \mathrm{~cm} / \mathrm{s}$ (14 in./s); $25.4 \mathrm{~cm}$ (10 in.) with the speed at $30.5 \mathrm{~cm} / \mathrm{s}$ (12 in./s); or $30.5 \mathrm{~cm}$ (12 in.) with the speed at $25.4 \mathrm{~cm} / \mathrm{s}$ (10 in./s) to achieve the thickness of 1.5 mils with $95 \%$ level of confidence. These results were calculated based on the Eq. (1), using the unit of inch.

Using the nonlinear regression procedure in SAS software package, it was determined through trial and error that the thickness measurement data for these experiment settings fit the exponential density function, which was

$$
Y=C e^{(-\theta X)}
$$

where $X=$ distance coordinate on Section A or B of the steel strip ( $X=0$ at the corner of the feature); $Y=$ thickness corresponding to each $X$; and both $C$ and $\theta=$ parameters of the exponential density function. Table 1 shows the values of the exponential density function parameters for the different spray gun settings. A total of three experiments were conducted in the lab to develop the exponential density function for each spray gun setting. Twelve thickness measurement points were taken for each experiment. For the $45^{\circ}$ pitch-angle setting the thickness distribution functions on Sections A and B (shown in Fig. 4) were the same because A and $\mathrm{B}$ were symmetrical. When the value of the pitch angle was changed, the thickness distribution functions on Sections A and B were no longer the same. For Section A the thickness increased near the corner area and dropped quicker along the distance when the pitch angle got smaller. The thickness decreased for Section B when the angle got smaller. Based on the experiment results, the spray gun pitch angle at $45^{\circ}$ was the best setting because it produced the widest effective width on both Sections A and B: an effective width is a section of the overall spray painting width on which no single thickness measurement is less than the specified thickness. Whenever possible, the pitch angle should be set at $45^{\circ}$ for painting the IBBC feature.

Laboratory experiments demonstrated that multiple linear regression models could be established between the coating thickness and the process planning parameters for different bridge features. The thickness distribution functions for the IBBC feature were exponential density functions for both flat surfaces that form the feature. For the web-surface feature, based on the previous experiments the thickness distribution function was a logistic density function if the spray gun was set perpendicular to the bridge surface, and a gamma function if the gun was set at other angles (Bai and Bernold 2001). The knowledge gained from the experiments was used to develop the $\mathrm{IP}^{3}$.

\section{IP ${ }^{3}$ Development}

Fig. 5 shows the overall structure of the $\mathrm{IP}^{3}$, which has two major components: (1) the process planning generator and (2) the parameter editor. Before running the process planning generator, a user needs to have the following information (input): (1) required coating thickness from the project specification; (2) bridge feature(s); (3) dimensions of the painting area; (4) spray gun constraint; and (5) distance constraint. Spray gun and distance constraints represent the presence of obstacles in the project site

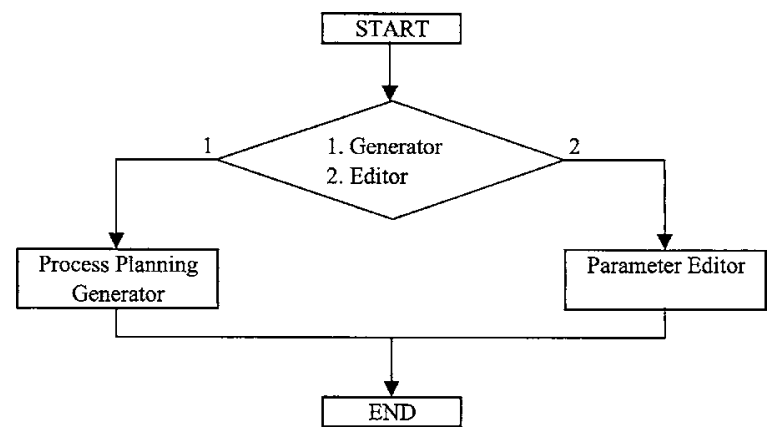

Fig. 5. Overview of the structure of the $\mathrm{IP}^{3}$ 


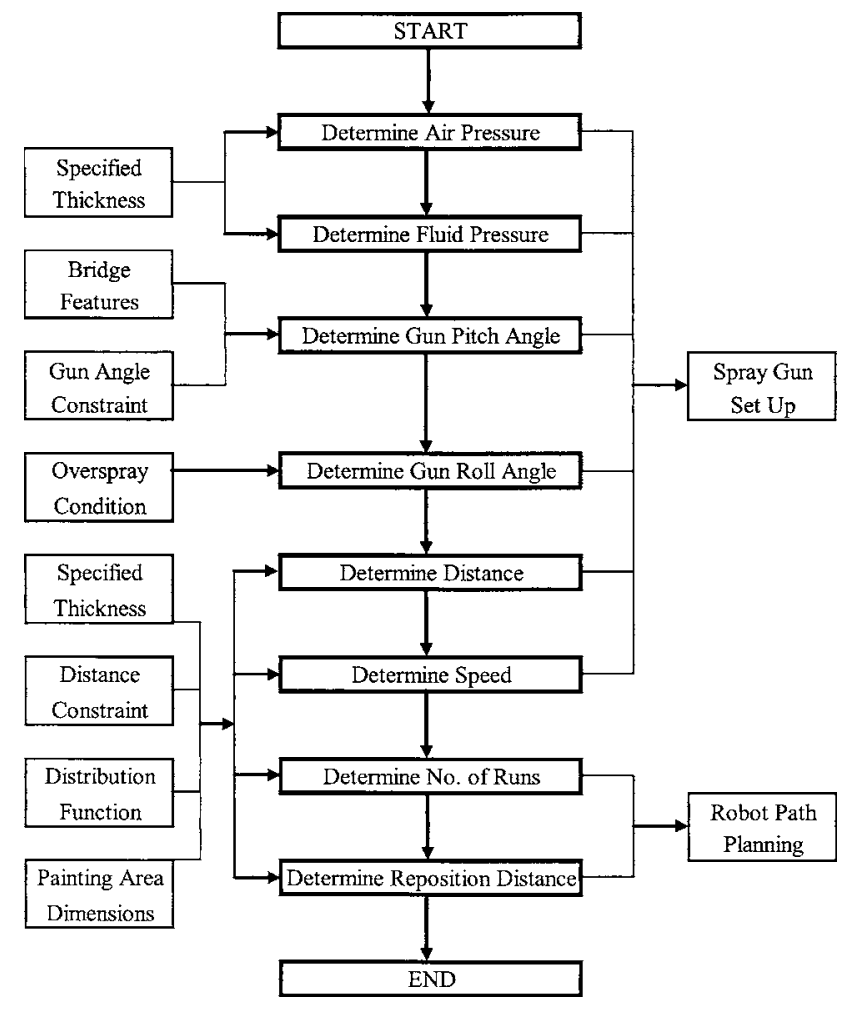

Fig. 6. Overview of the process planning generator

that prevent the operator from setting the spray gun at certain angle and/or distance. The vision system can be used to detect the bridge feature(s) and dimensions as described previously. Because the painting operation generally follows the paint removal operation and both operations use the same robot with different end effectors, the spray gun angle constraint and the distance constraint are known through the painting removal operation (Moon and Bernold 1995).

After running the process planning generator, eight painting process planning parameters (output) are generated for the operator to set up the spray gun and conduct the robot path planning. They are (1) air pressure; (2) fluid pressure; (3) spray gun pitch angle; (4) spray gun roll angle; (5) distance between spray gun and bridge surface; (6) spray gun moving speed; (7) number of spray runs; and (8) reposition distance between two adjacent spray runs. Then a trial spray painting is performed and monitored using the vision system in real time. If there is no problem in coating quality, the spray painting on bridge surface will continue. Otherwise, modifications of the parameters are needed. In the $\mathrm{IP}^{3}$ environment the operator provides the information about problems to the parameter editor, and a new set of process planning parameters is generated. The operator resets the spray painting system and starts painting again. This process will continue until satisfactory on quality is achieved. The creation of the parameter editor is the subject for future research. This paper presents the development of the process planning generator.

Fig. 6 shows the structure of the process planning generator that provides eight process planning parameters. Selections of parameter values are based on two criteria: (1) satisfying the required quality; and (2) minimizing the total direct cost of the spray painting operation. The following sections describe how each parameter is chosen.

\section{Selecting the Air and the Fluid Pressures}

The air and the fluid pressures are selected based on the coating thickness specified in the project specification. Most of the bridge painting projects require 1.5 mils coating thickness for each layer. Results of the lab experiments indicated that the air and the fluid pressures needed to be set at 137.8 and $3,445 \mathrm{kPa}$ (20 and $500 \mathrm{psi}$ ), respectively, for 1.5 mils thickness (Bai and Bernold 2001).

The relationship between the paint thickness and the spray pressures can be represented using an IF-THEN-ELSE conditional statement of AutoLISP language. The statement is explained as the following: "IF the condition is true, execute the THEN (first) expression; IF it is not true, execute the ELSE (second) expression." A multiple IF routine called "COND Structure" is also available in AutoLISP that can be used to handle any number of test conditions.

\section{Selecting the Spray Gun Pitch and Roll Angles}

The spray gun pitch angle is the angle between the central axis of the spray gun and the bridge surface to be painted. If the painting area is a plane surface, the gun needs to be set up perpendicular to the surface, which means the pitch angle is $90^{\circ}$ (Bai and Bernold 2001). If the area includes a right angle such as the IBBC feature, the pitch angle should be set at $45^{\circ}$ if there is no physical constraint, which was described in the section entitled "Data Analyses."

The spray gun roll angle is the angle formed between the orifice of the gun and the vertical axis ( $Y$-axis). Most of the time the roll angle is set at $0^{\circ}$. It is possible that the spray painting width may be larger than the feature dimension. Where painting such a feature, the overspray paint will reach adjacent object(s) or the environment. An effective method for addressing this problem is to reduce the spray width by rotating the spray gun orifice (changing the roll angle). The required value of the roll angle is determined based on the dimension of the feature and the spray width under a specific setting. Currently, the $\mathrm{IP}^{3}$ only assigns $0^{\circ}$ to the roll angle; and further research is needed so the roll angle can be set up at different degrees.

\section{Selecting Distance, Speed, Number of Runs, and Reposition Distance}

Values of the distance, the speed, the number of runs, and the gun reposition distance between two spray runs are selected based on the criteria that the specified painting quality and the minimum total direct cost of the spray painting operation will be achieved. The total direct cost is defined as the materials cost plus the operation cost that is written as follows:

$$
T_{C}=M_{C}+O_{C}
$$

where $T_{C}=$ total direct $\operatorname{cost}(\$) ; M_{C}=$ material cost $(\$)$; and $O_{C}=$ operation cost $(\$)$. The material cost is determined based on the flow rate of the spray gun, the material (paint) unit cost, and time the gun is in operation. It can be described as follows:

$$
M_{C}=F_{R} M_{\mathrm{UC}} S_{T}
$$

where $F_{R}=$ flowrate of the spray gun $(\mathrm{L} / \mathrm{s}) ; M_{\mathrm{UC}}=$ material unit cost $(\$ / \mathrm{L})$; and $S_{T}=$ spray time (s). The flowrate is a function of the spray gun tip size and the fluid pressure, and is available from the spray gun manufacturer. Because the material unit price is 


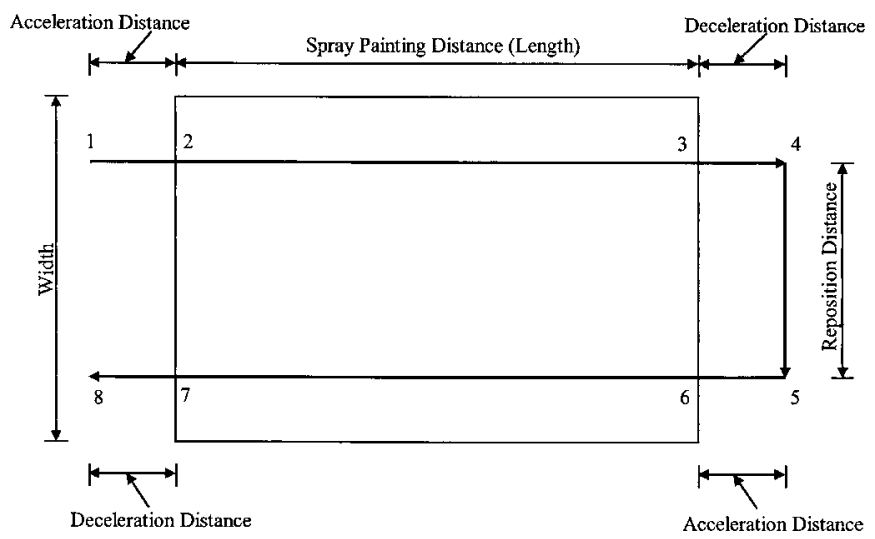

Fig. 7. Spray gun moving path for a hypothetical painting operation

usually known in the market, the only unknown variable in Eq. (4) is the spray time.

The operation costs include the equipment costs and labor costs, and can be defined as

$$
O_{C}=\left(E_{\mathrm{UC}}+L_{\mathrm{UC}}\right) O_{T}
$$

where $E_{\mathrm{UC}}=$ equipment unit cost $(\$ / \mathrm{s}) ; L_{\mathrm{UC}}=$ labor unit cost $(\$ / \mathrm{s})$; and $O_{T}=$ operation time (s). The equipment unit cost and the labor unit cost can be determined using current market rates or historical data, so the only unknown variable in Eq. (5) is the operation time.

Fig. 7 shows a spray gun moving path for a hypothetical painting operation with two spray runs and one reposition. To prevent appearance defects such as coating runs, the moving path must include acceleration and deceleration distances. Both distances are assumed to be equal to the spray gun moving speed $\left[S_{P}\right.$ $(\mathrm{cm} / \mathrm{s})]$ times one second. The terms used to describe the different segments of the moving path are defined as follows:

- Spray gun travel distance $\left(T_{D}\right)(\mathrm{cm})$ : from Points 1 to 8;

- Spray run $\left(S_{R}\right)(\mathrm{cm})$ : from Points 1 to 4 , and from Points 5 to 8 ;

- Spray painting distance $\left(P_{D}\right)(\mathrm{cm})$ : from Points 2 to 3 , and from Points 6 to 7;

- Acceleration distance $\left(A_{D}\right)(\mathrm{cm})$ : from Points 1 to 2, and from Points 5 to 6;

- Deceleration distance $\left(D_{D}\right)(\mathrm{cm})$ : from Points 3 to 4 , and from Points 7 to 8 ; and

- Reposition distance $\left(R_{D}\right)(\mathrm{cm})$ : from Points 4 to 5 .

If the spray gun moving speed and the dimensions of the area [length $(\mathrm{cm})$ and width $(\mathrm{cm})]$ are known, spray time $\left[S_{T}(\mathrm{~s})\right]$ can be determined using the spray painting distance $\left(P_{D}\right)$ divided by the speed. Operation time $\left[O_{T} \mathrm{~s}\right]$ can be calculated using the spray gun travel distance $\left(T_{D}\right)$ divided by the speed. Thus, the relationship between spray time and operation time can be represented in the following equation:

$$
S_{T}=O_{T}-2 N_{R}-\left(N_{R}-1\right) R_{D} / S_{P}
$$

where $N_{R}=$ number of spray runs. The assumptions for this equation are: (1) it takes one second for the spray gun to travel the acceleration distance (from Points 1 to 2 or from Points 5 to 6) or the deceleration distance (from Points 3 to 4 or from Points 7 to 8 ) and (2) the spray gun moving speed during painting (from Points 2 to 3 and from Points 6 to 7 ) and the reposition distance $\left(R_{D}\right)$ for the entire operation will remain constant. Substituting Eq. (4) for the material cost, Eq. (5) for the operation cost, and
Eq. (6) for spray time, the total cost [Eq. (3)] can be written as follows:

$$
\begin{aligned}
T_{C}= & \left(L_{\mathrm{UC}}+E_{\mathrm{UC}}+F_{R} M_{\mathrm{UC}}\right) O_{T}-2 F_{R} M_{\mathrm{UC}} N_{R} \\
& -F_{R} M_{\mathrm{UC}}\left(N_{R}-1\right) R_{D} / S_{P}
\end{aligned}
$$

The labor unit cost $\left(L_{\mathrm{UC}}\right)$, the equipment unit cost $\left(E_{\mathrm{UC}}\right)$, the material unit cost $\left(M_{\mathrm{UC}}\right)$, and the flow rate $\left(F_{R}\right)$ are usually known or can be estimated using historical data. Values of the operation time $\left(O_{T}\right)$, the number of runs $\left(N_{R}\right)$, and the reposition distance $\left(R_{D}\right)$ relate to the required coating thickness, the dimensions of the painting area, and the thickness distribution functions that were investigated previously [e.g., Eq. (2)].

Knowing the thickness distribution functions and total direct cost formula [Eq. (7)], the minimization by enumeration method is used to determine the distance, the speed, the number of runs, and the reposition distance that will achieve the required quality and the minimum total direct cost for a spray painting operation. The algorithm for implementing this method is described as follows.

- Step 1: Determine whether there is an obstacle to prevent the operator positioning the spray gun.

- Step 2: Set up the spray gun at distance 20.3, 25.4, or $30.5 \mathrm{~cm}$ $(18,10$, or 12 in., respectively) if there is no impediment. If there is an obstacle, the gun has to be set up at distance to avoid the obstacle. The method to handle this situation is the topic for future research.

- Step 3: Select all possible speeds for each possible distance. For example, at a distance of $30.5 \mathrm{~cm}$ (12 in.), the speed could be $25.4,30.5$ or $35.6 \mathrm{~cm}(10,12$, or $14 \mathrm{in}$., respectively) per second.

- Step 4: Determine the thickness distribution function for each combination of spray settings.

- Step 5: Calculate the number of runs based on the specified thickness (from project specifications), the dimensions of the area to be painted, and the thickness distribution function for each combination. With the required thickness plus the thickness distribution function, it is possible to calculate the required overlap dimensions between two spray runs in order to achieve the required thickness. The number of runs to cover the entire painting area can be determined using the thickness distribution function, the overlap dimensions between two spray runs, and the dimensions of the painting area.

- Step 6: Calculate the reposition distance based on the thickness distribution function and the number of runs for each combination with the condition that the overlap between the two spray runs must be greater or equal to the specified thickness.

- Step 7: Calculate the operation time based on the spray run $\left(S_{R}\right)$, the number of runs, the reposition distance, and the speed for each combination.

- Step 8: Calculate the total direct cost [using Eq. (7)] for each combination and select the distance, the speed, the number of runs, and the reposition distance that result the lowest total direct cost.

Using this algorithm, the bridge painting operation may achieve not only the minimum total direct cost but also the required quality.

\section{Field Experiments}

The developed $\mathrm{IP}^{3}$ was tested at the equipment depot at the NCDOT. The purpose of the field tests was to validate whether 


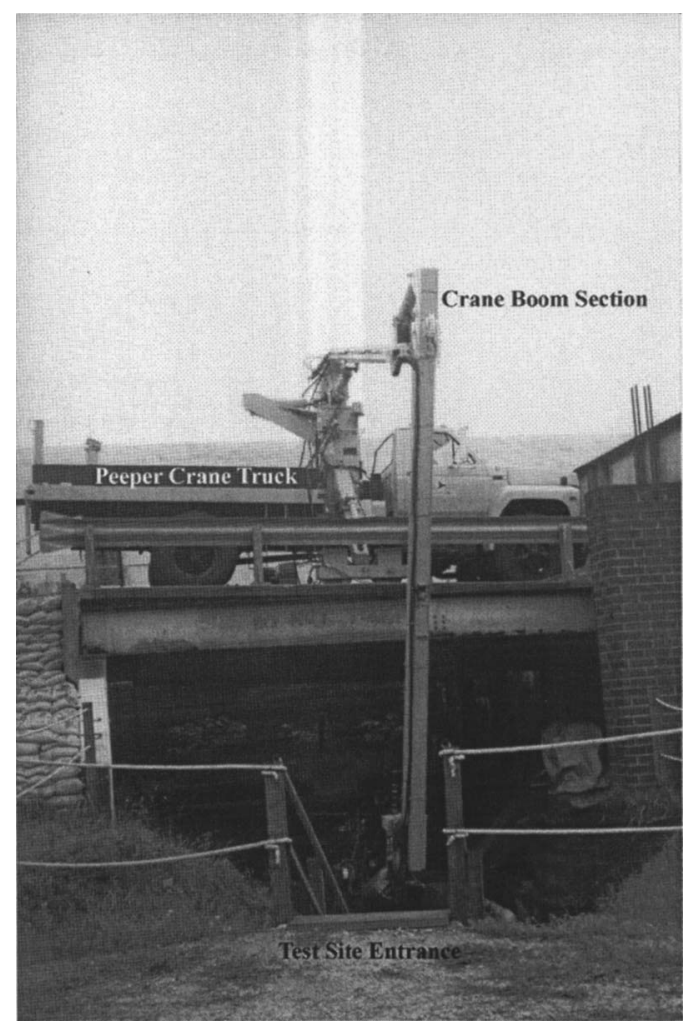

Fig. 8. View of the field experiment site

the painting quality could be achieved using the values of parameters provided by the $\mathrm{IP}^{3}$. A prototype robotic bridge painting system was built with major test apparatus including (1) a modified Peeper crane truck with three crane boom sections; (2) a robotic arm; (3) a spray gun; (4) a spray pump; (5) an air compressor; (6) a vision system; (7) robotic system control hardware and software; and (8) a personal computer with the $\mathrm{IP}^{3}$ program. Fig. 8 shows a view of the testing site, and Fig. 9 presents the robotic arm with the spray gun.

The crane boom is made up of three sections of which the third section was retrofitted. An actuated platform with a linear sliding table was built for positioning the robotic arm. The platform was attached to the end of the third section of crane boom. The sliding table provided independent linear movement for the robot arm. The developed vision system and ultrasonic sensors were mounted on the platform to measure the dimensions of a painting

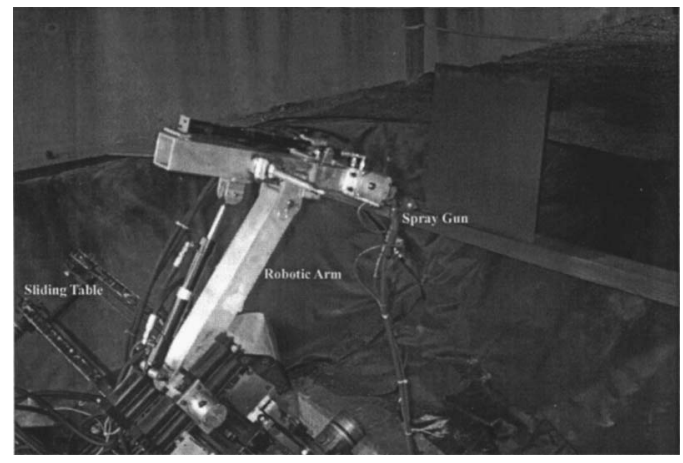

Fig. 9. Robotic arm with a spray gun area and the distance between the spray gun and the steel surface. The sensory data were also used for accurate deployment of the robotic painting system under the bridge deck.

Conditions of field tests were set up as follows: (1) required paint thickness was 1.5 mils; (2) bridge feature was outside-websurface (OWS); (3) painting area dimensions (length $\times$ width) were $61.0 \mathrm{~cm}$ by $38.1 \mathrm{~cm}$ (24 in. by $15 \mathrm{in}$.); and (4) there were no physical obstacles. After running the $\mathrm{IP}^{3}$ program, the following values were assigned to the eight process planning parameters including: (1) $138 \mathrm{kPa}$ (20 psi) to the air pressure; (2) $3,445 \mathrm{kPa}$ (500 psi) to the fluid pressure; (3) $90^{\circ}$ to the spray gun pitch angle; (4) $0^{\circ}$ to the spray gun roll angle; (5) $30.5 \mathrm{~cm}$ (12 in.) to the distance; (6) $30.5 \mathrm{~cm} / \mathrm{s}$ (12 in./s) to the speed; (7) 2 to the number of runs; and (8) $22.9 \mathrm{~cm}$ (9 in.) to the spray gun reposition distance between the two spray runs.

Two tests were conducted on the OWS feature in the field due to limited resources. A total of 21 thickness measurement points were taken from each field experiment. The data collection procedure in the field was the same as the one in the lab. Results of the tests demonstrated that both the coating thickness and appearance satisfied the quality requirements within the specified bridge painting area. Also, comparisons were made between the thickness measurement data and the predicted data from the developed thickness distribution function. The maximum difference between the measurement value and predicted value was 0.2 mils (measurement value - predicted value $=0.2$ mils). For some measurement points, the values were smaller than the predicted values. However, the percentage of difference was not greater than $20 \%$, which is the limit set by the Steel Structures Painting Manual (SSPC 1994).

\section{Contributions, Conclusions, and Recommendations}

Due to increasing government regulations on environment, health, and safety, the construction industry faces a great challenge in how to control the increase of the on-site bridge painting costs and also meet the regulations. A possible solution to address this challenge is to develop a robotic bridge painting system that can perform the painting operations in place of human beings. Because of the complexity of the construction environment, only a few robotic systems have been developed and used in construction operations. The research effort presented in this paper made a significant contribution to the advancement of robotic applications in the construction industry by developing the $\mathrm{IP}^{3}$, a key component in the planning and control model that manages onsite bridge painting operations. It also contributed to the practice of computer-integrated construction, specifically as it is extended to support robotic bridge painting operations.

A unique bridge feature scheme has been developed to represent components of a steel bridge. Thus, painting operations on a bridge can be broken down by each bridge feature. The feature scheme lays the foundation for automating the bridge painting process.

Factorial experiments were performed in the laboratory to determine the thickness regression model and the coating thickness distribution functions. The knowledge gained from the experiments became the foundation for building the $\mathrm{IP}^{3}$. The $\mathrm{IP}^{3}$, built based on a bridge feature scheme, integrates the painting process planning, robot path planning, cost optimization, and quality control functions. It can provide values for eight process planning parameters for setting up the spray gun and conducting the robot path planning. Field tests had been conducted to validate the per- 
formance of a prototype robotic bridge painting system equipped with the $\mathrm{IP}^{3}$. The outcome of the field experiments demonstrated that the coating thickness and appearance satisfied the quality requirements using the parameter values provided by the $\mathrm{IP}^{3}$. As a result, the robotic bridge painting becomes reality.

This research can be extended in several ways. First, additional field experiments should be conducted on other bridge features such as the IBBC feature to examine the accuracy of the $\mathrm{IP}^{3}$. Second, there is a need to further develop the parameter editor component so that the $\mathrm{IP}^{3}$ will be able to perform the necessary modifications on the process planning parameters. Modifications are necessary because sometimes it is impossible to set up the robotic bridge painting system right the first time. Third, the current $\mathrm{IP}^{3}$ can only assign $0^{\circ}$ to the spray gun roll angle. Further research is needed so that the roll angle can be set at different degrees to prevent overspray. This option is important because the overspray paint is dangerous to the environment. Fourth, the robotic system should be able to handle physical obstacles. For instance, if there is an obstacle in front of the robotic system, the spray gun needs to be set at a different pitch angle and distance that may be beyond the capability of current $\mathrm{IP}^{3}$. To address this problem, bridge structures need to be studied in detail and more lab experiments are required so that the knowledge base within the $\mathrm{IP}^{3}$ can be expanded. Finally, further research is needed to build the robotic painting system on a larger and more powerful crane truck. The truck can hold a larger sliding table so that robot arm can move a longer distance to cover large painting areas.

\section{Acknowledgments}

This research was funded by the North Carolina Department of Transportation. During the research, Dr. Dennis Boos and Dr. Leonhard Bernold at the North Carolina State University provided valuable advice. Their cooperation is greatly appreciated.

\section{Notation}

The following symbols are used in this paper:

$A_{D}=$ acceleration distance;

$C=$ parameter of exponential density function;

$D_{D}=$ deceleration distance;

$E_{\mathrm{UC}}=$ equipment unit cost;

$F_{R}=$ flow rate of the spray gun;

$L_{\mathrm{UC}}=$ labor unit cost;

$M_{C}=$ material cost;

$M_{\mathrm{UC}}=$ material unit cost;

$N_{R}=$ number of spray runs;

$O_{C}=$ operation cost;

$O_{T}=$ operation time;

$P_{D}=$ spray painting distance;

$R_{D}=$ reposition distance;

$S_{P}=$ spray gun moving speed;
$S_{R}=$ spray run;

$S_{T}=$ spray time;

$T_{C}=$ total direct cost;

$T_{D}=$ spray gun travel distance;

$X=$ distance coordinate;

$X_{1}=$ spray gun moving speed;

$X_{2}=$ distance between the spray gun and the corner of the IBBC feature;

$Y=$ the thickness corresponding to each $X$;

$Y_{t}=$ coating thickness; and

$\theta=$ parameter of exponential density function.

\section{References}

Akinci, B., Fischer, M., and Kunz, J. (2002). "Automated generation of work spaces required by construction activities." J. Constr. Eng. Manage., 128(4), 306-316.

Bai, Y., and Bernold, L. E. (2001). "Quality control parameters for robotic bridge painting." J. Constr. Eng. Manage., 127(2), 142-148.

Chang, T. C., Wysk, R. A., and Wang, H. P. (1991). Computer-aided manufacturing, Prentice-Hall, Englewood Cliffs, N.J.

Cho, Y. K., Haas, C. T., Sreenivasan, S. V., and Liapi, K. (2004). "Position error modeling for automated construction manipulators." J. Constr. Eng. Manage., 130(1), 50-58.

Freund, R. J., and Wilson, W. J. (1993). Statistical methods, Academic, San Diego.

Fu, Z., De Pennington, and Saia, A. (1993). "A graph grammar approach to feature representation and transformation." Int. J. Comput. Integr. Manuf., 6(1,2), 137-151.

Kim, S. K., Russell, J. S., and Koo, K. J. (2003). "Construction robot path-planning for earthwork operations." J. Comput. Civ. Eng., 17(2), 97-104.

Moon, S., and Bernold, L. E. (1995). "Robotic bridge paint removal field testing and evaluation of promising technologies." Special Rep., Civil Engineering Dept., North Carolina State Univ., Raleigh, N.C.

Navon, R., and Shpatnitsky, Y. (2005). "Field experiments in automated monitoring of road construction." J. Constr. Eng. Manage., 131(4), 487-493.

Oregon Department of Transportation (ODOT). (2004). "What it takes to paint the I-5 bridge." 〈http://www.odot.state.or.us/regionl/a_i5/ bridgepaint_whatittakes.html $\rangle$ (June 6, 2005).

S. G. Pinney \& Associates, Inc. (1985). "Painting inspection training course." Participant manual, Port St. Lucie, Fla.

Steel Structures Painting Council (SSPC). (1994). "Paint application specifications: Commentary on paint application, systems and specifications." Painting manual, Vol. 2, Pittsburgh, 405-408.

Skibniewski, M., and Hendrickson, C. (1988). "Analysis of robotic surface finishing work on construction site." J. Constr. Eng. Manage., ASCE, 114(1), 53-68.

Tokioka, S., Ishigami, S., Sekiguchi, R., Wada, M., Inagaki, H., and Sakai, S. (1989). "Robotized painting by the wall surface-finish robot (FR-1)." Proc., 6th Int. Symp. on Robotics in Construction in San Francisco, Construction Industry Institute, Austin, Tex., 531-538.

Warne, K. M. (1994). "Investigation of process control variables for an automated painting machine." MS thesis, Civil Engineering Dept., Univ. of Texas at Austin, Austin, Tex. 